\title{
TRABALHO, EDUCAÇÃO E HEGEMONIA NOS ANOS 1930 E 1940 NO BRASIL ANÁLISE A PARTIR DO IDORT
}

\author{
Eraldo Leme Batista* \\ Doutorando na FE-Unicamp \\ eraldolbatista@gmail.com \\ Marcos Roberto Lima** \\ Mestrando na FE- Unicamp \\ lima2782@terra.com.br
}

\section{RESUMO:}

Neste texto, analisamos o processo de fundação do IDORT $^{1}$ (Instituto de Organização Racional do Trabalho) e os objetivos propostos para esta instituição, tendo por pressuposto o entendimento de que com a criação deste Instituto, tornam-se mais explícitos conceitos referentes à educação para o trabalho, educação profissional, uma vez que a Revista IDORT, principal meio utilizado para divulgar o pensamento dos industriais paulistas no período, apresentava claramente a sua ideologia, atribuindo à educação papel fundamental como instrumento disciplinador dos trabalhadores. Ao analisar a critica realizada por diferentes autores, procuramos a compreensão do processo que culminou na consolidação de um novo projeto societário não mais caracterizado pelo caráter agrário exportador, mas que se realiza por de uma via de consolidação pelo alto, sem ruptura, marcada pela criação de uma racionalidade urbano industrial, mediante uma reforma caracterizada por seu caráter repressor, mas que buscava, sobretudo, impor-se como um novo consenso.

Palavras-chave: IDORT, hegemonia, educação profissional.

\section{WORK, EDUCATION AND HEGEMONY IN 1930 AND 1940 IN BRAZIL ANALYSIS FROM IDORT}

\begin{abstract}
ABSTRAT
In this paper, we analyze the process of founding the IDORT (Institute for Rational Organization of Labor) and the proposed goals for this institution, taking for granted with the understanding that the creation of this institute, become more explicit concepts regarding education for work, vocational education, since the magazine IDORT, the main medium used to disseminate the thinking of industrial Sao Paulo in the period, clearly showed their ideology accorded education role as a means of disciplining workers. When considering the criticism made by different authors, we seek to understand the process that culminated in the consolidation of a new corporate design no longer characterized by exporting agricultural character, but which is held by a consolidation path at the top, without breaking, characterized by the creation a rational industrial city, through reform characterized by its repressive character, but he sought, above all, to establish itself as a newconsensus.
\end{abstract}

Keywords: IDORT, hegemony, professional education. 
Qual o papel cumprido pelos industriais brasileiros articulados em torno do projeto de desenvolvimento industrial das décadas de 1930 e 1940 no Brasil? Para responder a essa questão, podemos partir do pressuposto apresentado por Gramsci nos cadernos do cárcere:

Deve-se observar o fato de que o empresário representa uma elaboração social superior, já caracterizada por uma certa capacidade dirigente e técnica (isto é, intelectual): ele deve possuir uma certa capacidade técnica, não somente na esfera restrita de sua atividade e de sua iniciativa, mas também em outras esferas, pelo menos nas mais próximas da produção econômica (deve ser um organizador de massas de homens, deve ser um organizador da "confiança" dos que investem em sua empresa,dos compradores de sua mercadoria, etc.). Se não todos os empresários, pelo menos uma elite deles deve possuir a capacidade de organizar a sociedade em geral, em todo o seu complexo organismo de serviços, até o organismo estatal, tendo em vista a necessidade de criar as condições mais favoráveis à expansão da própria classe; ou pelo menos, deve possuir a capacidade de escolher os "prepostos" (empregados especializados) a quem confiar esta atividade organizativa das relações gerais exteriores à empresa. Pode-se observar que os intelectuais "orgânicos" que cada nova classe cria consigo e elabora em seu desenvolvimento progressivo são, na maioria dos casos, "especializações" de aspectos parciais da atividade primitiva do tipo social novo que a nova classe deu à luz (GRAMSCI, 2006, Vol. II, pp.1516)

Para Gramsci, os diferentes grupos sociais que nascem no terreno de uma função essencial no mundo da produção econômica, criam de forma orgânica uma intelectualidade, cuja incumbência seria criar homogeneidade e consciência da própria função, não só no campo econômico, mas perpassando as esferas política e social.

A partir da assertiva gramisciana de que "o empresário capitalista cria consigo o técnico da indústria, o cientista da economia política, o organizador de uma nova cultura, de um novo direito", sendo entendido como uma elaboração social superior com capacidade técnica e organizativa, procuramos analisar o papel do empresariado brasileiro e sua estratégia hegemônica de imposição de um novo consenso através da criação do IDORT.

Outro importante pressuposto da análise ora apresentada, é que a formação da "grande massa do povo", processo já observado por Marx no desenvolvimento da manufatura, acompanhado por contradições, uma vez que cria uma uniformidade estacionária que corrompe a coragem de sua mente:

Ela destrói mesmo a energia de seu corpo e o incapacita a empregar suas forças com vigor e perseverança, a não ser na operação parcial para a qual foi adestrado (grifo nosso). Sua habilidade em seu oficio particular parece assim ter sido adquirida à custa de suas virtudes intelectuais, sociais e guerreiras. Mas, em toda sociedade industrial e civilizada, esse é o estado no qual necessariamente tem de cair o pobre que trabalha (the labouring poor), isto é, a grande massa do povo" (1988, livro I, vol. 1, p. 271).

Para Marx, é fato que a divisão manufatureira apresentar-se como progresso histórico, no entanto, produz novas condições de dominação do capital sobre o trabalho. Ao mesmo tempo em que ela desenvolve a força produtiva social do trabalho, inviabiliza o 
desenvolvimento individual do trabalhador, apresentando-se como um meio de exploração civilizada e refinada (LIMA, 2009, pp. 3-4).

A partir da crise do modelo econômico agrário exportador, ainda vigente no Brasil ao final dos anos de 1920, enxergamos um fenômeno de estandardização de uma sociedade de novo tipo. Metodologicamente, procuramos o entendimento desse processo a partir da categoria gramsciana de intelectual orgânico que tem nos orientado na tentativa de compreensão da ação dos empresários brasileiros durante as décadas subseqüentes de 1930-1940. Lembrando que, segundo Gramsci: "A hegemonia nasce da fábrica e necessita apenas, para ser exercida, de uma quantidade mínima de intermediários profissionais da política e da ideologia" (GRAMSCI, 2006, Vol. 4, pp. 247-248).

Sobre a égide ideológica do grupo industrial brasileiro que tentava se impor e que, para tanto, utilizou-se da educação profissional como instrumento, buscava-se neste contexto a criação de uma sociedade racionalizada. Assim como no caso Americano, analisado por Gramsci, e que o levou a afirmar: "Na América, a racionalização determinou a necessidade de elaborar um novo tipo humano, adequado ao novo tipo de trabalho e de processo produtivo [...]" (idem), buscamos compreender a criação deste novo homem a partir da ação estratégica dos empresários brasileiros através da criação do IDORT.

Segundo Antonacci (1993), o IDORT surge a partir da experiência de diversos empresários paulistas envolvidos com as propostas de organização cientifica do trabalho, durante a década de 1920, "num momento de redefinição das práticas de dominação social". Será esse grupo de industriais, articulados em torno das idéias de organização e racionalização do trabalho, que irá fundar o IDORT ${ }^{3}$, buscando assegurar o crescimento de grupos "ligados ao estudo e aplicação dos postulados da administração cientifica". O IDORT foi o portador das mais modernas exigências da racionalização e organização do trabalho neste período histórico que se estende até os anos de 1940, configurando-se "na matriz de vários 'elos' que foram compondo a nova mentalidade e a nova ordem social" (ANTONACCI, 1993, p. 17).

Ao também analisar a Organização Científica do Trabalho no Brasil, Tenca nos mostra que esse princípio de organização cientifica do trabalho:

(...) ganha força somente no final da década de 1920, e passa a ser disseminado de maneira mais efetiva a partir de 1931, com a criação do Instituto de Organização e Racionalização do Trabalho (IDORT), logo após a criação, em 1928, do Centro das Indústrias do Estado de São Paulo (CIESP), pólo aglutinador da grande indústria (2006, p. 30).

A partir da década de 1930, diversos industriais tornam-se adeptos das idéias tayloristas no Brasil, e é buscando implementar o taylorismo nas empresas que se organizam e fundam o IDORT, em 23 de Julho de 1931, em reunião realizada na sede da Associação Comercial de São Paulo. Cunha (2005?) nos informa que esta entidade desempenhou um papel importante sobre o ensino profissional não só em São Paulo, mas também no restante do país. No entanto, entendo que a questão do ensino profissional, acessível e voltado para formação dos pobres, somente se oficializará de fato em 1937, a partir do movimento da escola nova, com a elaboração da Constituição de 1937.

O IDORT foi criado em 1931, porém as idéias tayloristas no Brasil, já eram difundidas e defendidas por engenheiros e industriais no inicio do século XX, conforme as indicações de Antonacci (1993):

Se as idéias e práticas da administração científica tomaram posição na década de 20 - como resposta patronal à organização operária por 
transformações racionais nas condições de vida e de trabalho -, foi ao longo das décadas subseqüentes que suas modificações expandiram-se em ritmos, desdobramentos e fases, conforme as conjunturas e o jogo de forças sociais. Incorporando lutas e reivindicações sociais com soluções técnicas, as práticas racionalizadoras invadiram diferentemente a vida social ao reordenarem espaços, redimensionarem tempos e reorientarem relacionamentos sociais, num processo que se estendeu até a década de 60 , quando outros problemas e questões deixaram à mostra as mesmas conflituosas e contraditórias faces do capitalismo dominante (ANTONACCI, 1993, p. 32).

Esta pesquisadora expõe também o seu entendimento sobre a fundação do IDORT e as estratégias dos industriais paulistas, que pretendiam transformar o espaço fabril e implantar novos métodos de trabalho que aumentassem a produção com dimensões do "fazer-se da burguesia industrial paulista, enfrentando as potencialidades dos trabalhadores". As propostas de organização e racionalização do trabalho, difundidos pelo IDORT, segundo Antonacci, foram "ampliando, diversificando e infiltrando por toda a vida social, cultural e política, através de múltiplos e variados mecanismos de poder, administrando, economicamente e politicamente a tudo e a todos" (ANTONACCI, 1993, p. 17).

Outra autora que pesquisou a organização do IDORT foi Weinstein (2000), que em sua analise observa que a criação do IDORT foi resultado do acelerado crescimento e aceitação das idéias de racionalização. Conforme a compreensão desta autora:

A fundação do IDORT em 1931 foi apenas um dos muitos sinais do crescente entusiasmo pela racionalização entre os líderes da classe industrial. Mais uma vez, Roberto Simonsen tentou estabelecer um programa para a indústria, esboçando sua estratégia num discurso pronunciado no Instituto Mackenzie (...) Simonsen aproveitou a ocasião para analisar os problemas que dificultaram o desenvolvimento industrial brasileiro na década anterior. A solução que ele propôs para esses problemas, como era de se esperar, foi a organização racional da produção (WEINSTEIN, 2000, p. 87).

Para Tenca (2006, p. 30), o IDORT constituiu-se, “(...) numa das principais agências na luta pela imposição de uma vontade política particular, a da grande indústria paulista, de forma singular, já que se apresenta como prática estatal, embora conduzida, sobretudo nas décadas de 1930 e 1940, por uma instituição de iniciativa privada”.

Ao analisar pesquisas desenvolvidas por diversos autores sobre o IDORT, e ao observar as considerações de Tenca (2006), concordamos com a afirmação deste autor de que "a ação idortiana caracteriza-se como uma prática político-pedagógica de longo alcance". Conforme seu entendimento:

O conceito de trabalho do IDORT deriva da grande indústria mecanizada, da indústria moderna, portanto entendida como fator trabalho. Com a grande industria, o trabalho, despojado de sua materialidade, transformado definitivamente em mercadoria e apresentando-se como ahistórico, na as forma abstrata, penetra no social nomeando, agora, todo fazer humano como trabalho. Se tudo é trabalho, é possível aplicar os seus princípios racionalizadores em cada uma das múltiplas formas de fazer (TENCA, 2006, p. 31). 
Ao verificarmos o discurso burguês no interior do IDORT, a partir das pesquisas realizadas por diversos estudiosos e pesquisadores, Antonacci (1993), Cunha (2005), Pichelli (1997), Manfredi (2003), Kuenzer (2002), Tenca (2006), Weinstein (2000), Moraes (2003), constatamos que o mesmo já estava, na década de 1930, pautado “(...) no controle do operariado, na eliminação dos conflitos e no progresso industrial, procurando apresentar-se como única possibilidade de progresso da nação brasileira" (PICHELLI, 1997, P. 18).

Ao mesmo tempo em que a burguesia fazia um discurso ideológico de conciliação de classe, através da disciplina e colaboração, todos unidos em prol do progresso do país, propondo que os patrões e os operários se unissem na defesa dos interesses mútuos que levariam ao desenvolvimento industrial e que garantiriam a todos uma parcela de riqueza, buscava formas para conter as organizações de trabalhadores e suas ideologias comunista, socialista e anarquista, que deveriam ser neutralizadas, uma vez que, questionando, atrapalhavam o projeto industrial do país. (PICHELLI, 1997, p. 18).

Antonacci (1993) nos informa, por exemplo, que Simonsen, defende as idéias de racionalização e organização do trabalho, como ciência, e que:

A ciência promoveria uma sociedade solidária e harmônica, estava contida a reiteração da representação de uma sociedade organicamente composta, em clara oposição à sociedade contraditoriamente constituída em torno da luta de classes. Nesta direção, indicando sintomas sociais da nova organização e antevendo alianças e contrapontos à difusão do marxismo e da luta de classes, Simonsen revelou o outro ponto de chegada da racionalização (1993, p.103).

Esta pesquisadora nos mostra, ainda, que o pensamento deste autor tem claramente o objetivo de enfraquecer, ou mesmo eliminar as resistências operárias, a luta de classes e as idéias marxistas no meio operário. Simonsen entendia que "o desenvolvimento contínuo da cultura técnica e profissional, reclamada e recomendada pelos sindicatos operários, vão arrefecendo, naturalmente a luta de classes anunciada e preconizada por Karl Marx" (SIMONSEN, apud ANTONACCI, 1993, p. 103).

Assim como Antonacci (1993), Weinstein (2000) observa que o industrial Roberto Simonsen tinha bem claro seus objetivos com a organização do IDORT e suas defesas apaixonadas pela organização e racionalização do trabalho. Simonsen não esconde/disfarça sua tese e demonstra claramente a questão ideológica com relação às idéias marxistas. Este industrial defendia:

(...) uma era de harmonia social decorrente da reorganização científica da sociedade. Depois de inspirar uma política de trabalho avançada, a racionalização iria evoluir para um 'sistema político' baseado na 'razão e no conhecimento técnico'. Em seguida Simonsen dissertou sobre 'um verdadeiro equilíbrio entre os elementos que constituem as forças vivas da produção. A racionalização tem profundos efeitos sociais e contraria de forma patente as idéias fundamentais do marxismo. (...) a aceitação do controle operário na solução de problemas econômicos, tudo isso contribui para neutralizar a luta de classes prevista por Karl Marx (WEINSTEIN, 2000, p. 88).

Ou seja, os principais defensores da organização científica do trabalho deixavam evidentes suas propostas de organização não somente da indústria, mas da sociedade como 
um todo, e que suas idéias eram fundamentais para neutralizar a luta de classes e cooptar os trabalhadores.

Concordo com a análise dos pesquisadores citados acima, pois entendo que o discurso ideológico e a prática industrial dos principais membros do $\mathrm{IDORT}^{4}$, tinham por objetivo cooptar os trabalhadores para uma sociedade harmônica, sem conflitos, de colaboração, cujo verdadeiro objetivo era desqualificar o discurso formulado pelas lideranças operárias "rearticulando o espaço fabril, educando o operariado segundo os princípios da ética do trabalho e desse modo, consolidar o projeto hegemônico da burguesia industrial" (PICHELLI, 1997, p. 77).

Em sua análise sobre o IDORT e as estratégias dos industriais, Antonacci (1993), observa que um dos objetivos era "quebrar a autonomia e o poder desses grupos operários, que nas formas de trabalho e de organização expressavam uma elaboração cultural de vida através de concepções e disposições de tempos e espaços, de costumes e comportamentos, enfim, todo um modo de viver e se relacionar disseminado pela sociedade" (ANTONACCI, 1993, p. 46).

Antonacci (1993) constata que era objetivo dos industriais ligados ao IDORT "reestruturar o espaço fabril para conter a organização da classe trabalhadora". Informanos ainda que "os ideólogos do IDORT, queriam exercer um maior controle sobre os operários, submetendo-os a técnicos especializados, e também eliminar muitas funções pela simplificação do processo de trabalho" (ANTONACI, 1985, p. 96-97)

Os ideólogos do IDORT entendiam que este Instituto tinha um papel importante a cumprir, pois deveria incluir em seus objetivos “(...) a pesquisa e o intercâmbio de idéias, a aplicação de métodos científicos e a transformação dos inimigos de classe em colaboração para "prosperidade geral"” (WEISTEIN, 2000, p. 89).

Roberto Simonsen ${ }^{5}$, por exemplo, engenheiro e empresário foi um defensor da racionalização do trabalho nas indústrias brasileiras a partir das idéias de Taylor. Em 1918, em reunião com empresários e trabalhadores, proferiu um discurso entusiasmado sobre a racionalização do trabalho. Para Simonsen:

A prosperidade do Brasil no pós-guerra, com ênfase em novos métodos de produção, mais científicos e eficientes, que acarretariam a elevação tanto dos lucros quanto do padrão de vida, por meio da redução dos custos. (...) a redução dos custos de produção não se faria à custa de seus salários, mas antes por meio de uma 'máxima eficiência do trabalho', que seria obtida com uma 'perfeita organização na qual, por disposições inteligentemente adotadas, as perdas de tempo e os esforços nãoprodutivos sejam reduzidos ao mínimo'. (...) os verdadeiros princípios de cooperação cordial entre patrões e operários iriam predominar, em função dessa 'perfeita organização' (WEISTEIN, 2000, p. 31).

Percebemos no discurso desde entusiasta do taylorismo a concepção de colaboracionista de classe, de cooperação cordial, como mecanismo para se viabilizar sua proposta, possibilitando elevação dos lucros. Verificamos que estas idéias tornam-se mais enfáticas na década de 1930, com a fundação do IDORT e também a partir de governo Vargas que tinha um viés industrialista formado nas idéias positivistas.

Entendemos que a criação do IDORT, tinha um papel central, estratégico, que era de difundir o ideário da racionalização no setor industrial e também no Estado, além de fortalecer os industriais paulistas. No período histórico, circunscrito aos anos de 1930 e 1940, o IDORT foi fundamental na disputa hegemônica entre os industriais e o setor 
agrário, não só pelo aparelho de Estado, mas também de convencimento e cooptação dos trabalhadores.

Neste sentido, concordo com Tenca (2006)

O IDORT, criado em 1931, embora já praticamente organizado em 1929, surge, com a bandeira da racionalização do trabalho, como a grande agência responsável, direta e indiretamente, pela multiplicação de inúmeras outras voltadas para a busca da realização da acumulação do capital, pela intensificação da exploração do trabalho, numa ampla cruzada pela ocupação e controle do tempo do trabalhador (TENCA, 2006, p. 39).

Simonsen, Mange ${ }^{6}$ e outros industriais entendiam que o Estado tinha um papel fundamental na divulgação da ideologia de "cooperação de classe", sociedade "harmoniosa" entre capital e trabalho. Estes industriais, defensores da organização racional do trabalho, definiam ainda o Estado como "um mecanismo potencialmente útil para disciplinar os membros da própria classe (WEINSTEIN, 2000, p.71). Ou seja, não bastava somente disciplinar os trabalhadores no espaço fabril, era urgente que o Estado colaborasse para a disciplina de setores industriais que ainda tinham certa resistência às idéias de organização racional do trabalho.

Em 1930, sobe ao poder Getulio Vargas, ocorrendo um processo de transição que nada tinha de "revolucionário", configurando-se em um processo de rearranjo do bloco de poder, porém, sem mudar as estruturas de poder, mantendo-se a velha estrutura latifundiária do país. Conforme entende Antunes (1980), este processo deu-se "pelo alto", não havendo a participação da classe trabalhadora, excluída de qualquer participação, ficando nítida a conciliação estabelecida entre as frações dominantes.

Este processo foi importante para o inicio do capitalismo industrial no país, caracterizando-se, porém, pela falta de ruptura, pela "conciliação entre o velho e o novo, entre vários segmentos representantes dos interesses agrários e mesmo dos setores urbanos emergentes" (ANTUNES, 1980, p. 67). Apesar de ter sido um processo marcado pela conciliação de classes, torna-se importante ressaltar que o mesmo não se deu de forma tranqüila, ocorrendo fissuras no interior da classe dominante devido às disputas "pelo maior controle do aparelho do Estado buscando uma participação mais decisiva na nova configuração do poder" (ANTUNES, 1980, p. 69).

Antunes (1980) observa que após a "ascensão" de Vargas ao poder, o Estado passa a implementar a política sindical com o objetivo principal de "controlar" e "desmobilizar" os operários. Conforme o autor:

O Estado iniciou a formulação de uma política sindical, cujo aspecto essencial era o seu caráter controlador e desmobilizador, condição esta necessária não só para que o movimento operário não ultrapassasse os limites impostos pela nova ordem política, mas também para que se assegurassem as condições mínimas garantidoras da instauração de uma nova ordem econômica dirigida para a industrialização (ANTUNES, 1980, p. 74).

Os industriais, defensores das idéias de organização e racionalização do trabalho, verão suas idéias sobre "paz social", "cooperação de classe", sociedade "harmoniosa" defendidas por Vargas, como nos informa Vianna (1976): “A 'paz social' era procurada através de concessões e benefícios concretos, a que não era insensível a massa dos 
assalariados. A possibilidade do controle operário incluirá necessariamente uma legislação minimamente protetora do trabalho" (VARGAS, apud VIANNA, 1976, p. 150).

Estes mesmos industriais ficarão ainda mais entusiasmados, ao ouvirem o pronunciamento feito por Vargas, nos primeiros anos de seu governo, afirmando que:

O individualismo excessivo, que caracterizou o século passado, precisava encontrar limite e corretivo na preocupação predominante do interesse social. Não há nessa atitude nenhum indício de hostilidade ao capital, que, ao contrário, precisa ser atraído, amparado e garantido pelo poder público. Mas o melhor meio de garanti-lo está, justamente, em transformar o proletariado numa força orgânica de cooperação com o Estado e não o deixar, pelo abandono da lei, entregue à ação dissolvente de elementos perturbadores, destituídos dos sentimentos de Pátria e de Família (VARGAS, apud, ANTUNES, 1980, P. 74).

Além de relacionar a importância da cooperação do proletariado com o Estado, Vargas critica as lideranças estrangeiras por serem "perturbadoras da ordem" e não terem sentimentos de amor a pátria.

Até 1930, as mobilizações, greves e protestos, contra a jornada de trabalho, condições de trabalho e exploração, eram constantes. Vargas, ao mesmo tempo em que reprimia duramente os movimentos dos trabalhadores, liderados pelos anarquistas e comunistas, buscava criar políticas que visassem cooptar os trabalhadores, intensificando também o discurso ideológico de uma sociedade harmônica, sem classes, e que todos estavam do mesmo lado, não existindo patrões e operários, mas empregados e empregadores (GIANOTTI, 2007, p. 131).

Gianotti (2007) assevera que a proposta de um novo sindicalismo, defendida por Vargas, significava que os mesmos "deveriam defender a conciliação de classes e zelar pela harmonia de interesses entre capital e trabalho. As idéias-chaves passarão a ser 'colaboração de classe' e 'paz social'. Não haveria mais lutas. O Estado seria o pai de todos" (GIANOTTI, 2007, 131).

Os empresários buscavam diversos métodos para controlar a classe trabalhadora, cooptando, reprimindo e explorando trabalhadores estrangeiros, mas, assim como os autores já citados acima, Gianotti, constata que com Vargas o projeto burguês de controle sobre os trabalhadores ganha a força e sustentação do Estado. “(...) Ao mesmo tempo, queriam controlar o movimento operário, através da repressão e da cooptação. Defendiam que a classe trabalhadora poderia participar do desenvolvimento da nação, mas sempre, evidentemente, de maneira controlada" (GIANOTTI, 2007, p. 91).

Ao analisar a relação do Governo Vargas e os industriais, Tenca (2006), observa que os industriais

(...) vão ganhando espaço no interior do Estado e isso contribui para que ocorra um processo de crescimento do aparato burocrático, orientado segundo os princípios da racionalização do trabalho, reforçando o caráter 'científico' da 'nova' administração que, segundo os seus mais fiéis defensores, transformava a atividade estatal em ação conduzida por imperativos técnicos e não por interesses públicos (TENCA, 2006, p. 41).

Há o consenso na bibliografia ora referenciada de que o discurso ideológico tinha como objetivo construir uma sociedade harmônica, sem conflitos e com colaboração de classe ${ }^{7}$. 
Entendo que o discurso ideológico dos industriais ganha força na década de 30, e se em alguns momentos se utilizava a força, a violência para reprimir greves e protestos dos trabalhadores, por outro lado, vai se alterando as estratégias empresariais no sentido de cooptar os trabalhadores para suas teses.

Entendo, assim como Weisntein (2000, p. 75), que a defesa entusiasmada da "paz social", era uma questão ideológica, pois os industriais ligados ao IDORT entendiam que a proposta de organização racional do trabalho somente teria êxito se houvesse cooperação e contribuição dos trabalhadores. No entanto, estes não demonstravam simpatia pelas idéias "inovadoras" de organização racional do trabalho.

Segundo Weinstein (2000, p. 75), a questão da "ordem social", não era

[...] um aspecto de pouca importância para os industriais adeptos da racionalização, uma vez que eles consideravam a paz social tanto um prérequisito quanto uma conseqüência da implantação de seu projeto. A necessidade de harmonia entre as classes tornava inevitáveis determinadas concessões, mesmo as de natureza 'não cientifica'.

Ao analisar esta mesma questão, Antonacci (1993) observa que os industriais ligados ao IDORT, desde a década de 1920 estavam realizando experiências tayloristas no espaço fabril, defendendo a idéia de que a racionalização deveria ser pensada para a sociedade como um todo. Observa a autora que o taylorismo extrapolou o espaço fabril e articulou-se:

(...) a vários interesses e movimentos de controle social, entretecendo práticas e discursos que se pautavam por retirar dos trabalhadores e outros sujeitos sociais, a capacidade de decidir e trilhar caminhos próprios, ao expropria-los de seus saberes, aspirações, proposições e fixar-lhes conhecimentos, organizações, necessidades e capacidades codificadas pela racionalidade de nova ordem social. A ordem corporativista, edificada e operacionalizada por meios e designações técnicas, sentenciando lugares e atividades, derivou de alterações na forma de autoridade e exercício do poder, que colocam em relevo as questões políticas inerentes ao taylorismo e possibilitam ter presente que suas práticas, nos mundos do trabalho, marcaram o advento desse modo de organização da vida social e estatal (ANTONACCI, 1993, P. 25).

Esta mesma autora observa que as idéias de Fayol foram também muito valorizadas pelos membros do IDORT, encontrando ressonância na:

(...) lógica totalitária latente em São Paulo, na década de 30, fundamentaram as atividades do IDORT, no seu empenho em absorver e responder aos entraves à racionalização, numa perspectiva de que não só o trabalho, mas a sociedade como um todo é organizável, passível e sujeita a intervenções de técnicos. Trabalho e sociedade são moldáveis e administráveis, de acordo com determinados e específicos interesses: foram o raciocínio e o procedimento da razão vitoriosa, organizada no IDORT pela burguesia industrial paulista (ANTONACCI, 1993, p. 31).

Em um período histórico (1920-1930) marcado pela organização da classe trabalhadora através dos movimentos anarquista, socialista e também dos comunistas, que fundam o PCB em 1922, a burguesia estava alarmada com a capacidade de organização, mobilização e enfrentamento da classe trabalhadora. Neste sentido, buscará diversas 
alternativas para barrar este movimento, via leis de expulsão do país, repressão, cooptação e também educação profissional, com o objetivo de adestrar, orientar, disciplinar os trabalhadores.

O discurso realizado pelos industriais ligados ao IDORT, convocando para cooperação de classe, consistia em uma ação ideológica visando a cooptação e envolvimento. Na prática, mostrava-se contraditório, pois o controle no espaço de trabalho era cada vez mais rígido, e se não bastasse isso, os empresários passaram a criar métodos de controle sobre a vida dos operários fora das fábricas. Para viabilizar este controle extra fabril, criaram as "vilas-cidadelas", que eram um "conjunto de moradias e agrupamentos coletivos edificados pelas próprias fábricas para seus operários" (ROLNIK, 1994, p. 100).

Ao analisar a situação dos trabalhadores no inicio do século no Brasil, Rolnik (1994) nos informa que a cidadela:

(...) é um bairro completo: casas, escola, creche, armazém, praça, campo de futebol, igreja, gerido pelo proprietário da indústria para seus operários. Nela, o tempo fora da fábrica também está sujeito às normas que imperam durante a jornada de trabalho. Quem mora na vila-cidadela deve ter um comportamento 'em casa' $e$ 'na rua' tão disciplinado $e$ organizado quanto o comportamento 'na fábrica'. Isto é garantido por uma série de controles presentes nas cidadelas: obrigatoriedade de freqüentar a igreja, toque de recolher à noite, bailes vigiados. Além destes, evidentes, a própria identificação patrão/senhorio já significa maior controle sobre o trabalhador: a cessão da casa era apresentada como um privilégio para o operário, alcançado por este graças a um comportamento exemplar na produção, ou seja, regularidade, produtividade, dedicação e, sobretudo, submissão. Muitas vezes tinham o direito de morar na vila da fábrica as famílias que possuíssem mais do que três membros trabalhando naquela indústria, o que estimulava a própria família a manter a autovigilância, já que comportamentos irregulares de qualquer um dos seus membros moradores-trabalhadores implicavam a perda da casa. Todas estas formas de controle nada mais fazem do que estabelecer uma vida coletiva heterônoma: o bairro popular dominado pela fábrica (ROLNIK, 1994, P. 100-101, grifos meus).

Diversas formas de controle sobre o trabalhador foram buscadas, sendo que, além das vilas-cidadela, muitos industriais criaram também a "vila higiênica", que segundo Rolnik, se diferenciava da estrutura dos cortiços:

A vila, padrão popular proposto na legislação, se diferencia do cortiço por conter, no interior de cada unidade, as áreas de cozinhar, lavar, banhar e defecar. As unidades, ainda geminadas e dando para pátio ou corredor comum, possui mais de um cômodo. A vila tem, portanto, mais separações do que o cortiço. Além disto, as atividades que mais são coletivas e misturadas no cortiço passam a ocorrer nos fundos de cada casa, longe da vista dos vizinhos (ROLNIK, 1994, p. 100).

Rolnik observa que as intenções dos industriais em controlar a vida dos trabalhadores para além dos muros das fábricas não era uma questão fácil, pois os becos e pátios dos bairros populares contribuíam para que as pessoas conversassem sobre os problemas cotidianos. Neste período, os anarquistas tinham forte atuação nos bairros, o que facilitava as mobilizações, que rapidamente ganhavam as ruas: 
Nascidos nos becos e pátios dos bairros populares se convertiam em assembléias públicas, nos salões, esquinas, praças. Sair às ruas, paralisando e modificando a ordem reinante na cidade, era a estratégia de disseminação e articulação dos setores oprimidos e explorados proposta pelos anarquistas (ROLNIK, 1994, p. 104).

Cristina Campos (1988) analisa o controle sobre os trabalhadores a partir da criação do consenso, momento em que as idéias da classe dominante passam a constituir-se no próprio modo de ser do trabalhador, já não mais limitado ao espaço fabril. Segundo a autora:

\begin{abstract}
A questão do controle e disciplinarização ultrapassam o lócus fabril, invadindo a vida cotidiana, o espaço de vida privado das pessoas. Esta invasão total em todas as instâncias da vida humana visava, para além das simples adequações, estabelecer novos métodos de organização da produção, da racionalização do processo de trabalho. Tinha uma proposta que objetivava a construção de uma ética baseada na disciplina, uma estratégia de controle e de mecanismos que permitissem a transformação de idéias de uma classe em idéias dominantes da sociedade, fazendo com que certos valores e normas aparecessem dotados de universalidade. Para que este processo de introjeção se realizasse eficazmente havia que se fazer o enquadramento do indivíduo. Enquadrava-se também o tempo e o espaço do cotidiano familiar, as condutas, afetos e emoções. Mediante estas táticas, a vida privada dos indivíduos foi atrelada aos destinos de uma determinada classe social, a burguesia. O corpo, o sexo, os sentimentos conjugais, parentais e filiais passaram a ser utilizados como instrumentos de diferenciação e dominação (CAMPOS, 1988, p. 18).
\end{abstract}

Concordamos com a autora, no entanto, é importante acrescentar que havia resistência de movimentos organizados pelos anarquistas, socialistas ou comunistas, como explicita Rolnik (1994), que a partir de organizações populares, buscavam a rua como forma de protestar contra as condições de moradia ou para condenar as ações truculentas do poder público.

A propaganda ideológica burguesa tinha um papel estratégico, pois ao mesmo tempo em que os movimentos contestatórios eram reprimidos, buscava-se cooptar os trabalhadores para as idéias da racionalização do trabalho, sob alegação de que isso aumentaria a produção, beneficiando os patrões e também os trabalhadores, que teriam melhores salários.

A dimensão positivista da ideologia burguesa se evidenciava através do discurso dos industriais na revista do Idort (1932, p. 6). A funcionalidade da sociedade é comparada ao corpo humano, e este corpo humano estava fragilizado, perturbado, pois alguns membros estavam doentes (leia-se: classe trabalhadora), comprometendo-se o funcionamento do organismo social: “(...) no organismo social esse absurdo é tentado de várias formas e as chamadas lutas de classe não são mais do que uma luta de órgãos que pretendem dirigir o organismo, isto é, fígados e estômagos que pretendem ser cérebros, de vez em quando" (REVISTA IDORT, 1932, apud, PICHELLI, 1997, p. 20-21, grifos meus).

Além de considerarem a organização dos trabalhadores uma doença para a sociedade, os mesmos são identificados com o estômago deste organismo, deixando entender que o cérebro é a classe dominante e que, mesmo sendo inferiores, estes trabalhadores ligados as idéias anarquistas, socialistas e comunistas, se achavam na 
condição de dirigir o organismo social, sentindo-se capazes de assumir a função de cérebro.

O trabalho qualificado era compreendido neste período não somente como meio de se manter a ordem e evitar a desordem, mas também como "instrumento inteligente de produção industrial", para garantir e implementar sua ideologia, dispondo-se de instituições educacionais como Liceus de Artes e Ofícios e os asilos desvalidos (CUNHA, 2005a, p. 30).

Formação/educação profissional para os trabalhadores era um dos principais objetivos do IDORT, sendo que Lourenço Filho e Roberto Mange tornaram-se os responsáveis pela questão educacional no interior desta organização empresarial. Tenca (2006, p. 40), ao analisar a questão da educação no interior do IDORT, entende que:

Na educação, o Instituto de Organização e Racional do Trabalho exerceu um papel dos mais importantes na vasta empresa voltada para o controle do tempo do trabalhador, em âmbito regional e nacional. Das inúmeras atividades desenvolvidas nessa área, penso ser importante citar, considerando o tema deste trabalho, a Escola Livre de Sociologia e Política e os cursos voltados diretamente para a formação de trabalhadores.

Importante lembrar que o principal entusiasta e articulador da criação da Escola Livre de Sociologia e Política era Roberto Simonsen, Presidente da FIESP e fundador do IDORT. Este empresário defenderá que a função desta escola seja a formação de trabalhadores.

Em sua inauguração, em 1933, Simonsen deixou claro quais eram os objetivos definidos para a escola:

(...) Essa escola tem que possuir um tal programa que possa, além de seu curso normal, esboçar um plano de pesquisas sociais e coordenar a documentação já existente, dirigindo a formação de estatísticas adequadas, promovendo publicações periódicas de monografias e inquéritos, pesquisando os casos especiais pela aplicação dos métodos de observação e inquirição diretos, incentivando a formação de operadores capazes de tais cometimentos e enfim coordenando tudo quanto possa interessar ao perfeito conhecimento do meio em que vivemos e dos elementos necessários à solução dos problemas de governo (SIMONSEN, apud TENCA, 2006, p. 40).

O IDORT foi fundamental para a discussão e reorganização do ensino profissional no Brasil nos anos de 1930, mas foi na década de 1940 que os industriais viram muitas de suas propostas serem implementadas.

Foi durante o Estado Novo (1937-1945) que ocorreu a regulamentação do ensino profissional no Brasil, a partir da reforma Capanema (1942), conhecida também como Leis Orgânicas do Ensino ${ }^{8}$. Esta reforma estruturou o ensino profissional, reformulou o ensino comercial e criou o Serviço Nacional de Aprendizagem Industrial - SENAI.

Tenca (2006, p. 41), entende que o papel do IDORT, a partir dos anos 30:

(...) foi marcante na reorganização do ensino profissional no Brasil, na estruturação do Departamento de Administração do Serviço Publico (DASP); na criação do Sesi e do Sesc; na Reorganização Administrativa do Governo do Estado (Rage), em São Paulo; em iniciativas vinculadas 
direta ou indiretamente à Fiesp, como na criação da Escola Livre de Sociologia e Política, em 1933, antecipando-se mesmo à constituição da Universidade de São Paulo, criada em 1934, no governo de Armando Salles de Oliveira, que foi um dos fundadores e o primeiro presidente do IDORT em 1931. Esses fatos indicam a interferência direta dos representantes da indústria paulista na implementação de políticas sociais, de um lado, e, de outro, o investimento na reestruturação da burocracia, tanto no setor privado como em instituições governamentais (2006, p.41).

Ao mesmo tempo em que os industriais fundam a Escola Livre de Sociologia e Política para formação profissional dos trabalhadores que deveriam na trabalhar na indústria, que passava por alterações significativas, foi criada a Universidade de São Paulo, com o objetivo claro de formação da elite industrial, empresarial paulista.

Os industriais pensavam um projeto educacional para o país que possibilitasse a formação de um novo homem, "operários dóceis, saudáveis e produtivos, além de uma nova elite, capaz de comandar a sociedade dentro dos novos princípios da ordem burguesa" (PICHELLI, 1997, p.6).

Em seus estudos, Romanelli (2006) observa que vários fatores contribuíram para a restrição da importação de trabalhadores estrangeiros especializados:

(...) É conveniente lembrar que a época exigia uma redefinição da política de importação de pessoal técnico qualificado, como vinha acontecendo até então. A guerra estava funcionando como mecanismo de contenção da exportação de mão-de-obra dos países europeus para o Brasil. Até essa altura, não existira uma política adequada de formação de recursos humanos para a indústria, porque esta se vinha provendo de mão-de-obra especializada, mediante importação de técnicos. O período de guerra estava dificultando essa importação, do mesmo modo que dificultava a importação de produtos industrializados. Isso suscitava um duplo problema para o Estado: de um lado, ter de satisfazer as necessidades de consumo da população com produtos de fabricação nacional (...) o que significava ter de expandir o setor industrial brasileiro e, com isso, absorver mais mão-de-obra qualificada - e, de outro lado, já não poder contar com a importação desta, pelo menos no mesmo ritmo em que ela se processava (ROMANELLI, 2006, p. 155).

Romanelli nos informa que é a partir deste processo que surge a idéia dos industriais brasileiros de treinar trabalhadores nacionais, surgindo a partir desta preocupação a necessidade urgente de se criar uma escola de formação de trabalhadores. É neste contexto que irá surgir o SENAI.

Somando-se o descontentamento com os trabalhadores estrangeiros, mais os problemas em decorrência da guerra, cresce no interior do grupo dos industrialistas a necessidade de se criar esta escola. O Governo Federal criará um sistema de ensino paralelo ao sistema oficial, organizado em convênio com as indústrias através da CNI (Confederação Nacional das Indústrias) (ROMANELLI, 2006, p.155).

Constatamos que a preocupação com a formação profissional de trabalhadores brasileiros já estava clara no início do século XX, aprofundando-se com a criação do IDORT, na década de 1930, pois ao verificarmos a Lei $n^{\circ} 1.184$, de 3 de dezembro de 1909, podemos observar já neste período a preocupação com a educação dos jovens filhos dos operários, esta lei: 
Determinou a criação de escolas noturnas, na capital e no interior, especificando que elas deveriam localizar-se nas proximidades das fábricas e atenderem, exclusivamente, aos meninos operários ou filhos de operários. A prioridade de instalação dessas escolas seria daquelas que tivessem acomodações oferecidas pelas empresas, e o professor seria sempre provido pelo governo estadual. A articulação com as fábricas deveria se dar, também, na definição do horário escolar (CUNHA, 2005a, p. 141).

A partir dos apontamentos deste autor, verificamos a articulação entre o setor privado e o setor Estatal, que garantia que estas escolas tivessem como principal objetivo atender aos interesses da elite industrial. Em 1909, o governo do Estado de São Paulo estabelece contratos com o setor privado e instala escolas profissionalizantes com o objetivo de formar força de trabalho qualificada para o trabalho fabril.

Em sua pesquisa, Cunha (2005a) assevera que o texto da lei $n^{\circ} 1.192$, de 22 de dezembro de 1909, expressava a persistência da idéia do ensino profissional como algo destinado aos desvalidos, em consonância, aliás, com a exposição de motivos do decreto do presidente de República, desse mesmo ano:

Fica o Governo autorizado a contratar com estabelecimentos industriais, agrícolas ou beneficentes de reconhecida idoneidade, a educação profissional de menores pobres, não criminosos de ambos os sexos, que tenham mais de 11 anos de idade e que, por falta de proteção paterna ou tutelar, estiverem abandonados (CUNHA, 2005a, p. 142).

Com o decorrer do tempo, o debate em torno da educação profissional vai ganhando maior importância em diversos setores da sociedade: acadêmico, empresarial, governamental. A Constituição de 1937, por exemplo, em seu artigo ${ }^{\circ} 129$, determinou um papel inédito para o Estado, as empresas e sindicatos, no tocante à educação profissional das "classes menos favorecidas". Conforme este artigo:

O ensino pré-vocacional e profissional destinado às classes menos favorecidas é em matéria de educação o primeiro dever do Estado. Cumpre-lhe dar execução a esse dever, fundando institutos de ensino profissional e subsidiando os de iniciativa dos estados, dos municípios ou associações particulares e profissionais. É dever das indústrias e dos sindicatos econômicos criar, na esfera de sua especialidade, escolas de aprendizes destinadas aos filhos de seus operários ou de seus associados. A lei regulará o cumprimento desse dever como os auxílios, facilidades e subsídios a lhes serem concedidos pelo poder público (CUNHA, 2005b, p. 28).

Segundo Romanelli (2006), o Ministro de Vargas, Gustavo Capanema, dá início à reforma de alguns ramos do ensino, criando as chamadas Leis Orgânicas. As leis que estruturaram o ensino técnico-profissional começaram a ser promulgadas de forma gradativa, sendo que as leis do ensino técnico ficaram assim definidas:

a)- Em 30 de Janeiro de 1942, o decreto-lei ${ }^{\circ} 4073$ organizava o ensino industrial (Lei Orgânica do Ensino Industrial); b)- em 28 de dezembro de 1943, saía a Lei Orgânica do Ensino Comercial, pelo decreto-lei $\mathrm{n}^{\circ}$ 6.141 ; c)- e, em 20 de agosto de 1946, findo, portanto, o Estado Novo, 
saía o decreto lei 9.613, chamado Lei Orgânica do Ensino Agrícola (ROMANELLI, 2006, p. 154).

Ao analisar estes decretos, Romanelli (2006) destaca que a criação das escolas de aprendizagem foi de "(...) indiscutível valor da história do ensino profissional, pois revela uma preocupação do governo de engajar as indústrias na qualificação de seu pessoal, além de obrigá-las a colaborar com a sociedade na educação de seus membros”. Os trabalhadores técnicos eram importados, pois não existia no Brasil força de trabalho qualificada para realizar o trabalho no setor industrial (ROMANELLI, 2006, p.154).

A partir do texto apresentado, concluímos que a burguesia industrial brasileira, no período histórico analisado, tinha um projeto político de construção da hegemonia, instrumentalizado através de uma proposta educacional focada no desenvolvimento nacional a partir da industrialização. A educação deveria ser funcional às necessidades dos industriais, que buscavam impor seu projeto de sociedade de cunho industrial. Este pragmatismo é acompanhado por uma ação ideológica que busca a imposição de um novo consenso, naturalizando uma nova sociabilidade. Como observa Marx:

Não basta que as condições de trabalho apareçam num pólo como capital e no outro pólo, pessoas que nada têm para vender a não ser sua força de trabalho. Não basta também forçarem-nas a se venderem voluntariamente. Na evolução da produção capitalista, desenvolve-se uma classe de trabalhadores que, por educação, tradição, costume, reconhece as exigências daquele modo de produção como leis naturais evidentes (1988, vol. II, p. 267).

Para concretizar seu projeto hegemônico, a burguesia industrial brasileira cria o IDORT, como estratégia para divulgação de suas idéias sobre o "progresso" industrial, o que evidencia o caráter pedagógico de sua ação estratégica, ao mesmo tempo, o caráter sofisticado da racionalidade industrial imposta através de uma ação, aparentemente, pedagógica.

\section{REFERÊNCIA BIBLIOGRÁFICA}

ANTUNES, Ricardo. Classe operária, sindicatos e partido no Brasil: Da revolução de 30 até a Aliança Nacional Libertadora, Cortez, São Paulo, 1980.

ANTONACCI, Maria Antonieta M. A Vitória da Razão? O IDORT e a Sociedade Paulista, Marco Zero, São Paulo, 1993.

BATISTA, Roberto Leme \& GONZALEZ, Jorge Luiz Cammarano. Trabalho e Educação, Contradições do Capitalismo Global. Praxis, Londrina, 2006

BATISTA, Roberto Leme \& ARAÚJO, Renan. Desafios do Trabalho, Capital e Luta de Classes no Século XXI, Praxis, Londrina, 2003.

BATISTA, Roberto Leme \& TUMOLO, Paulo Sergio. Trabalho, Economia e

Educação: Perspectivas do Capitalismo Global, Praxis, Londrina, 2008. 
BATISTA, Eraldo L. \& LIMA, Marcos R.. A ideologia da Educação Profissional no interior da CUT: das lutas sociais à concertação social dos anos dos anos 90, Revista RET no 4,

CAMPOS, Cristina Hebling. O Sonhar libertário: movimento operário nos anos de 1917 a 1921, Pontes, Campinas, 1988.

CUNHA, Luiz Antônio. O ensino de ofícios nos primórdios da industrialização, Unesp, São Paulo, 2005a.

CUNHA, Luiz Antônio. O ensino industrial na irradiação do industrialismo, Unesp, São Paulo, 2005b.

GRAMSCI, Antonio. Cadernos do cárcere, Vol.2, 4ª edição, Rio de Janeiro, Civilização Brasileira , 2006.

LIMA, Marcos R. As contribuições de Gramsci à critica das estratégias educativas do terceiro setor e seu novo canto da sereia em educação, Revista RET $n^{\circ} 5$

MARX, Karl. O Capital: critica da Economia Política. $3^{\text {a }}$ edição, SP, Nova Cultural, 1988.

PICHELI, Valdir. O Idort enquanto proposta educacional no contexto de formação da hegemonia burguesa no Brasil (1930 - 1944), Tese Doutorado, FE/Unicamp, Campinas, 1997.

RIBEIRO, Maria Luiza Santos. Historia da Educação Brasileira, A Organização Escolar, Autores Associados, Campinas, 2003.

ROLNIK, Raquel. São Paulo, início da industrialização: o espaço e a política, In: Kowarick, Lúcio: As Lutas Sociais e a cidade, Paz e terra, São Paulo, 1994.

ROMANElli, Otaíza de Oliveira. Historia da Educação no Brasil, Vozes, Rio de Janeiro, 2006.

TENCA, Álvaro. Razão e Vontade Política: O Idort e a grande industria nos anos 30, Dissertação (Mestrado), Unicamp, Campinas, 1987.

TENCA, Alvaro. Senhores dos trilhos; racionalização, trabalho e tempo livre nas narrativas de ex-alunos do curso de ferroviários da antiga paulista, São Paulo, Unesp, 2006.

WEINSTEIN, Bárbara. (Re)formação da classe trabalhadora no Brasil, 1920-1964, Cortez: CDAPH-IFAN, São Paulo, 2000.

VIANNA, Luiz Werneck. Liberalismo e Sindicato no Brasil, Paz e Terra, Rio de Janeiro, 1976.

*Pesquisador integrante do Grupo de Estudos Gramsci e Educação e Membro da RET.

** Pesquisador integrante do Grupo de Estudos Gramsci e Educação. 
${ }^{1}$ Segundo Pichelli (1997), o IDORT: “(...) constitui-se com objetivo de estudar, aplicar e difundir os métodos de organização científica do trabalho. Com isso tem o intuito de aumentar o bem-estar social, por meio do acréscimo da eficiência do trabalho humano, em todos os seus ramos, expresso no máximo proveito, quer para o individuo, quer para a coletividade (...) é uma sociedade de estudos e de ação, voltada, imediatamente, ao melhor aproveitamento de todo esforço humano empregado em qualquer das múltiplas manifestações da atividade moderna, não só na indústria, mas também, na própria ciência e no trabalho intelectual, em tudo enfim, onde a arte de fazer e de administrar tenha de se fazer sentir" (Revista Idort apud, PICHELLI, 1997, p. 10-11).

${ }^{3}$ É importante destacar que antes da criação do IDORT, já havia sido fundada em 1930 a Organização Racional do Trabalho (ORT), buscando implementar as idéias tayloristas no Brasil. A ORT foi criado pela empresa Estrada de Ferro Sorocabana e tinha por objetivo solucionar os diversos problemas técnicos, administrativos e também de formação e aperfeiçoamento de pessoal. Segundo Cunha: "expressava o conjunto de teorias que surgiram a partir do século XIX inspiradas na doutrina de Frederick Taylor, que a chamou de Teoria de Administração Científica do Trabalho. Essa teoria tinha como objetivo final a obtenção do máximo de produtividade de cada trabalhador, apresentando a peculiaridade de poder ser utilizada com êxito em diferentes sistemas econômicos, como no capitalismo tardio e no socialismo nascente" (CUNHA, 2005a, p. 116).

${ }^{4}$ Entendemos que a criação do IDORT, foi resultado da organização dos empresários desde década de 20, liderados por Roberto Simonsen, entusiasta e defensor da organização científica do trabalho. Em 1928, por exemplo, este empresário liderou a organização e criação do centro das indústrias do Estado de São Paulo (CIESP). "Este passou a ser o centro ideológico e organizador dos industriais paulistas" (GIANOTTI, 2007, P. 90).

${ }^{5}$ Conforme Weinstein (2000), "Roberto Simonsen nasceu no ano de 1889, o último da monarquia brasileira e o primeiro no qual os proprietários brasileiros tinham que se valer apenas de trabalhadores livres como força de trabalho. O pai de Simonsen, Sydney Martin Simonsen, era um cidadão inglês de origem dinamarquesa e judia, que chegou ao Rio de Janeiro na década de 1870 para dirigir uma casa bancária inglesa". Este engenheiro, iniciou seus trabalhos na Southern Brazil Railway, anos depois, muda-se para a cidade de Santos, onde funda a Companhia Construtora de Santos. Simonsen trabalha em grandes empresas, tornando-se referência no setor industrial e torna-se referencia na divulgação das idéias tayloristas no Brasil. (WEINSTEIN, 2000, p. 35).

${ }^{6}$ Filho de diplomata, nascido na Suíça, fez os estudos primários em Portugal, secundários na Alemanha, formando-se em Engenharia pela Escola Politécnica de Zurich. Contratado em 1903, com idade de 28 anos, para lecionar desenho de máquinas na Escola Politécnica de São Paulo, irá influenciar várias gerações de engenheiros, 'que após passarem por suas mãos, ocupam altos cargos na burocracia estatal e nas empresas públicas’. Em 1931, participa da fundação do IDORT. (CAETANO, apud, MORAES, 2003, P. 240).

7 Todos deveriam contribuir para este projeto da classe dominante, que defendia a racionalização na sociedade e todos os setores da vida humana, o espaço fabril, o cotidiano das pessoas, o próprio Estado não deveria escapar das medidas salutares da organização racional, já que isto significava a adoção de método, técnica e organização, planejados para assegurar o mínimo de gastos, tanto de esforços como de material (PICHELLI, 1997, p. 25).

${ }^{8}$ Estes foram os decretos-lei, criados por Capanema em 1942/43:

- Decreto-lei n. 4.073, de 30 de janeiro de 1942, que organizou o ensino industrial;

- Decreto-lei n. 4.048, de 22 de janeiro de 1942, que instituiu o SENAI;

- Decreto-lei n.4.244 de 9 de abril de 1942, que organizou o ensino secundário em dois ciclos: o ginasial, com quatro anos, e o colegial, com três anos;

- Decreto-lei n.6.141, de 28 de dezembro de 1943, que reformou o ensino comercial.

RECEBIDO DIA 30 DE MAIO DE 2010

AVALIADO DIA 08 DE JUNHO DE 2010 